\title{
Bioplastic production using wood mill effluents as feedstock
}

M. Ben, T. Mato, A. Lopez, M. Vila, C. Kennes and M. C. Veiga

Water Science \& Technology, Vol 63 No 6 pp 1196-1202 IWA Publishing 2011

doi:10.2166/wst.2011.358

\begin{abstract}
Fibreboard production is one of the most important industrial activities in Galicia (Spain). Great amounts of wastewater are generated, with properties depending on the type of wood, treatment process, final product and water reusing, among others. These effluents are characterized by a high chemical oxygen demand, low $\mathrm{pH}$ and nutrients limitation. Although anaerobic digestion is one of the most suitable processes for the treatment, lately bioplastics production (mainly polyhydroxyalkanoates) from wastewaters with mixed cultures is being evaluated. Substrate requirements for these processes consist of high organic matter content and low nutrient concentration. Therefore, wood mill effluents could be a suitable feedstock. In this work, the possibility of producing bioplastics from to wood mill effluents is evaluated. First, wood mill effluent was converted to volatile fatty acids in an acidogenic reactor operated at two different hydraulic retention times of 1 and $1.5 \mathrm{~d}$. The acidification percentage obtained was $37 \%$ and $42 \%$, respectively. Then, aerobic batch assays were performed using fermented wood mill effluents obtained at different hydraulic retention times. Assays were developed using different cultures as inoculums. The maximum storage yield of $0.57 \mathrm{Cmmol} / \mathrm{Cmmol}$ was obtained when when the culture was enriched on a synthetic media.
\end{abstract}

Keywords: acidogenic fermentation, bioplastics, polyhydroxyalkanoates, sequencing batch reactor, volatile fatty acids, wood mill effluent. 


\section{Introduction}

Fibreboard production is one of the most important industrial activities in Galicia (Spain) in which great amounts of wastewater are generated producing a negative environmental impact. The properties of these wastewaters depend on type of wood, treatment process, final product, water reusing, etc. Nevertheless, these effluents are characterized by high chemical oxygen demand (COD) content, low $\mathrm{pH}$ values and nutrients scarcity. Anaerobic digestion is one of the most used processes to treat them. It works without oxygen supply, the amount of sludge generated is lower than in aerobic processes and it produces biogas, which can be used as fuel. The high COD and the low nutrient contents present in this kind of water makes it also feasible substrate to obtain polyhydroxyalkanoates (PHA).

PHA are polyesters of various hydroxyalkanoates which have plastic properties. These PHA are synthesised by bacteria as energy and carbon storage materials. Hence, they are completely biodegradable by microorganisms. Due to this properties PHA could be good substitutes of petroleum derived plastics.

Although PHA are already industrially produced their applications are limited to niche applications, and they are not yet considered as a commodity material because their production cost are still much higher than for synthetic polymers. Industrial production of PHA is based on the use of pure cultures and pure substrates. The price of PHA is highly dependent on substrate costs (Lee 1996). One way to reduce PHA price would be to use mixed cultures and cheap substrates (preferably waste organic carbon).

Recently, the use of wastewater as substrate and mixed cultures on PHA production has been reported in several research works (Dionisi et al. 2005; Albuquerque et al. 2007; Coats et al. 2007; Salmiati et al. 2007; Bengtsson et al. 2008a). Many studies use a synthetic VFA mixture in the experimental system. Surthridge et al. (2009) are working on PHA production from pulp and paper wastestreams. Bengtsson et al. (2008a, b) are also studying PHA production with different wastewaters, including paper mill effluents. However, paper mill wastewaters contain contaminants restulting from bleaching processes which are not present in wood mill effluents. Therefore, their characteristics could be different.

In this work, the possibility of using wood mill effluents as feedstock to produce PHA is suggested as it is a large source of organic carbon and has a low nutrient content. In order to evaluate the possibility of using this kind of waste, an acidogenic reactor was operated at two different hydraulic retention times (HRT) to produce VFA. The effluent derived from the acidogenic reactor was used as substrate in several aerobic batch assays where the feasibility of producing PHA was tested. In order to determinate the PHA production potential of the sludge enriched in PHA accumulating bacteria present in our laboratory at this moment, several assays were developed with two different cultures; one acclimated to fermented brewery wastewater and another one enriched on a synthetic medium containing a mixture of VFA as substrate.

\section{Materials and Methods}

\section{Influent wastewater}

The acidogenic reactor was fed with water collected from a wood industry producing medium density fibreboard (MDF). This mill uses pine and black poplar as raw material for its process, with a proportion of $80 \%$ and $20 \%$, respectively. The type of wood used in the fibreboard production process affects the composition of the final effluent and thus, the biodegradability of the wastewater. The VFA proportions obtained at the end of the fermentation could depend on the type of wood. 
Wastewater treatment plant of this mill consists of two units: flotation, anthracite filter, cartridge filters and reverse osmosis. During two months, samples have been collected weekly in different points of the treatment plant: raw waste- water, flotation outlet and reverse osmosis outlet (final effluent). General parameters of wastewater characterization were measured in each point, giving the average results shown in Table 1 . Water collected from flotation outlet was the influent used for acidogenic fermentation. The COD in this stream consisted of 30\% total sugars, 25\% VFA and 10\% ethanol, the remaining COD was of a more complex composition.

\begin{tabular}{|c|c|c|c|c|}
\hline \multirow[b]{2}{*}{ Parameter } & \multirow[b]{2}{*}{ Units } & \multicolumn{2}{|c|}{ Sample point } & \multirow[b]{2}{*}{3} \\
\hline & & 1 & 2 & \\
\hline $\mathrm{COD}_{\mathrm{T}}$ & $\mathrm{mg} / \mathrm{L}$ & 42,582 & 11,110 & 1,193 \\
\hline $\mathrm{COD}_{\mathrm{S}}$ & $\mathrm{mg} / \mathrm{L}$ & 14,767 & 10,540 & 1,132 \\
\hline $\mathrm{COD}_{\mathrm{S}} / \mathrm{COD}_{\mathrm{T}}$ & & 0.37 & 0.96 & 0.96 \\
\hline $\mathrm{BOD}_{5}$ & $\mathrm{mg} / \mathrm{L}$ & 6,422 & 3,922 & 220 \\
\hline $\mathrm{BOD}_{5} / \mathrm{COD}_{\mathrm{T}}$ & & 0.16 & 0.36 & 0.21 \\
\hline TSS & $\mathrm{mg} / \mathrm{L}$ & 13,874 & 60 & 4 \\
\hline VSS & $\mathrm{mg} / \mathrm{L}$ & 13,491 & 53 & 3 \\
\hline $\mathrm{NH}_{4}^{+}$ & $\mathrm{mg} / \mathrm{L}$ & 18.2 & 2.3 & 2.7 \\
\hline TKN & $\mathrm{mg} / \mathrm{L}$ & 241 & 109 & 11 \\
\hline $\mathrm{pH}$ & & 4.6 & 5.8 & 4.9 \\
\hline Alkalinity & $\mathrm{mg} / \mathrm{L}$ & 170 & 753 & 67 \\
\hline
\end{tabular}

\section{Experimental set-up}

\section{Acidogenic fermentation}

Wood mill effluent fermentation was carried out in a continuous stirred tank reactor (CSTR) with a useful volume of $1.6 \mathrm{~L}$ and a settler of $0.8 \mathrm{~L}$. Since there was no possibility of obtaining anaerobic sludge from the wood industry, the reactor was inoculated with biomass from the anaerobic reactor of a brewery industry wastewater treatment plant in Galicia (Spain) at concentration of $4 \mathrm{~g}$ VSS (volatile sus-pended solids)/L and kept at $30^{\circ} \mathrm{C}$. The reactor was operated at two different hydraulic retention times (HRT) of $1 \mathrm{~d}$ and $1.5 \mathrm{~d}$ resulting in average organic loading rates (OLR) of 5.6 and $2.9 \mathrm{~g} \mathrm{COD} / \mathrm{L} * \mathrm{~d}$, respectively. $\mathrm{pH}$ was kept at 5.5 by addition of $\mathrm{NaOH} 2 \mathrm{M}$ solution. These conditions were close in agreement with results obtained in previous experiments (unpublished results).

\section{PHA producing biomass enrichment}

Two different cultures were used in this study. The first one was enriched in a $1 \mathrm{~L}$ SBR (sequencing batch reactor) fed with fermented brewery wastewater (culture 1) at an OLR of $34 \mathrm{Cmmol} / \mathrm{L}^{*}$ cycle and the second one was got in a $1.5 \mathrm{~L}-\mathrm{SBR}$ fed with synthetic media containing acetic, propionic, butyric and n-valeric acids as substrate at an OLR of $27 \mathrm{Cmmol} / \mathrm{L}^{*}$ cycle (culture 2). The initial inoculum used to seed both reactors was the same. Both SBR were operated under aerobic dynamic feeding (ADF) conditions. Operational con-ditions fixed in both reactors were the same: SBR cycle of 12 hours, HRT of $1 \mathrm{~d}$ and solids retention time (SRT) of $7 \mathrm{~d}$. Air was supplied at a flow rate of $1 \mathrm{vvm} . \mathrm{pH}$ and temperature in the reactors were not controlled, but they were 
monitored. Nitrogen was added in a concentration of $1.4 \mathrm{Nmmol} / \mathrm{L}$. Table 2 shown the main operational parameters applied in the enrichment of the aerobic SBR.

Table 2: Operational parameters applied during the PHA producing biomass enrichment.

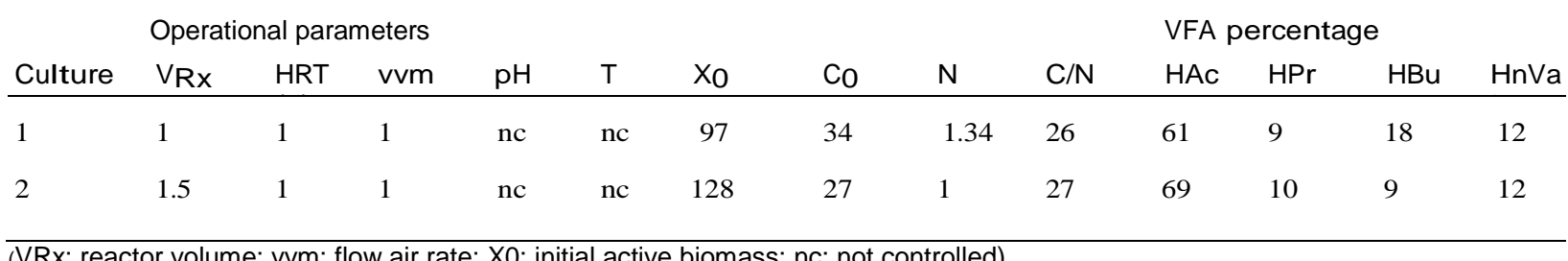

(VRx: reactor volume; vvm: flow air rate; X0: initial active biomass; nc: not controlled)

Aerobic batch assays

Aerobic batch assays were performed with the sludge from the enrichment reactors previously described. Assays using fermented wood mill effluent and synthetic media were performed in a $0.6 \mathrm{~L}$ vessel connected to a respirometer. Operational conditions were close to the ones in the SBR.

\section{Analytical procedures}

Total suspended solids (TSS), VSS, biochemical oxygen demand (BOD) and total Kjeldahl nitrogen (TKN) were measured as described in Standard Methods (APHA 1998). Total and soluble chemical oxygen demand $\left(\mathrm{COD}_{\mathrm{T}}\right.$ and $\mathrm{COD}_{\mathrm{S}}$, respectively) were evaluated by a method consisting in the acid digestion of the sample with dichromate at $150^{\circ} \mathrm{C}$. Ammonium and phosphate concentrations were determined by using colorimetric methods.

Volatile fatty acids (VFA) (acetate, propionate, butyrate, i-valerate and n-valerate) and ethanol concentrations were determined by high performance liquid chromatography (HPLC) using a Hewlett Packard chromatograph equipped with a Supelcogel C-610 column using an ultraviolet (UV) detector and a RI detector, respectively. Phosphoric acid $0.1 \%$ was used as mobile phase, with a flow of $0.5 \mathrm{ml} / \mathrm{min}$.

The column was kept at $30^{\circ} \mathrm{C}$. The wavelength for detection was set at $210 \mathrm{~nm}$. VFA concentrations were calculated using a calibration curve ranging from 25 to 3000 $\mathrm{mg} / \mathrm{L}$.

PHA were determined by gas chromatography (GC) following the method described by Braunegg et al. (1978), modified by Comeau et al. (1988) and Satoh et al. (1992). The method consists on the rupture of cell membranes and structures. Then, the PHA chains are hydrolysed and the monomers are methylated. The methylated monomers are extracted with chloroform, injecting the organic phase in a liquid-gas chromatograph. A calibration curve with $\mathrm{P}(\mathrm{HB}-\mathrm{HV})$ standard $(88 \% / 12 \%)$ corrected by an internal standard (heptadecane) was used to determinate hydroxybutyrate (HB) and hydroxyvalerate (HV) concentrations.

\section{Calculations}

\section{Acidogenic fermentation}

The total VFA concentration corresponds to the sum of acetate, propionate, butyrate, i-valerate and n-valerate con- centrations. The percentage of organic matter conversion into VFA was calculated as (mg COD-VFA in the effluent/mg COD in the influent)*100. The acidogenic activity was considered as mg of VFA in the effluent per $\mathrm{mg}$ of biomass in the reactor (both in $\mathrm{C} \mathrm{mg}$ ) and per liter. 
Aerobic batch assay

Sludge PHA content was determined as a fraction of VSS on a mass basis (\%PHA = PHA*100/VSS; PHA and VSS concentration in $\mathrm{g} / \mathrm{L}$ ). Biomass concentration is the sum of PHA content and active biomass (SSV $=$ PHA $+\mathrm{X}$; where $\mathrm{X}$ represents the active biomass). Active biomass was calculated considering all ammonia was used for growth. The PHA concentration corresponds to the sum of $\mathrm{HB}$ and $\mathrm{HV}$ monomers. PHA production $\left(\mathrm{Y}_{\mathrm{STO}}\right)$ on substrate consumed was calculated as the ratio between the overall amount of PHA and the total amount of substrate consumed. The specific HA production $\left(\Delta \mathrm{f}_{\mathrm{HA}}\right)$ was determined by substracting the initial specific $\mathrm{HA}$ concentration from the final specific HA concentration (Cmmol HA/Cmmol X).

\section{Results}

\section{Acidogenic fermentation}

Experiments were carried out at different HRT (1 and 1.5 d). VFA effluent concentration was quite similar for the two HRT tested. However, the VFA composition was different, with an increase of long-chain VFA concentration ( $\mathrm{HBu}$ and $\mathrm{HVal}$ ) at the higher HRT applied (Table 3). Acidification percentage was $37 \%$ at $1 \mathrm{~d}$ and $42 \%$ at $1.5 \mathrm{~d}$. Bengtsson et al. (2008a) obtained maximal acidification of 75\% at HRT of $1 \mathrm{~d}$ using a paper mill effluent, but this is slightly different of wood mill effluent, which could influence the conversion obtained.

The nature of the organic matter present in wood mill effluent might not be easily transformed into VFA. Total COD is composed in a $65 \%$ by the sum of VFA, sugars and ethanol, which could be easily transformed by acidogenic fermentation. Thus, other operation conditions need to be tested in order to improve the acidification of the wood mill effluent, at least until a $65 \%$ of acidification percentage. Still, the other $35 \%$ of total COD, in accordance with the BOD/COD ratio, could be formed by hardly degradable compounds, which usually appear in this kind of streams, so a pre-treatment could be needed in order to improve acidification above $65 \%$.

\begin{tabular}{|c|c|c|c|c|c|c|c|c|c|}
\hline HRT & VFA & $\mathbf{N}-\mathrm{NH}_{4}^{+}$ & $\mathrm{COD}_{0}$ & $\operatorname{COD}_{e}$ & HAC & HPr & $\mathrm{HBu}$ & HVal & \%VFA \\
\hline $1.0 \mathrm{~d}$ & 1731 & 25 & 5611 & 4594 & 1161 & 486 & 28 & 0 & 37 \\
\hline $1.5 \mathrm{~d}$ & 1422 & 2 & 4276 & 3299 & 725 & 551 & 97 & 43 & 42 \\
\hline
\end{tabular}

\section{PHA production}

Two different aerobic cultures were used to seed the PHA production from fermented wood waste, one enriched on brewery wastewater (culture 1) and the second one enriched in a synthetic medium (culture 2). Figure 1 shows a typical cycle of the SBRs where the biomass was enriched for PHA accumulating bacteria.
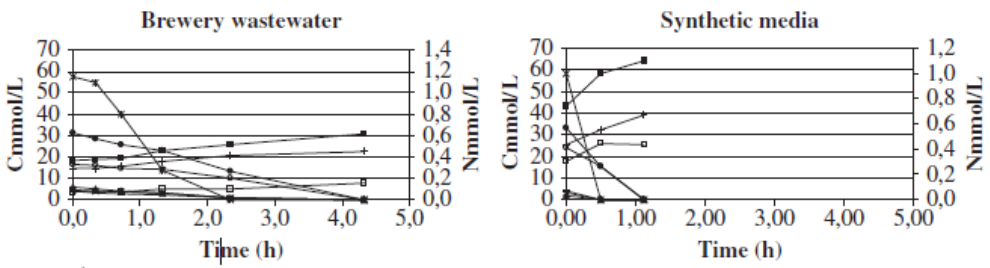
Both aerobic cultures used in these assays were previously submitted to feast/famine conditions and operated during several months in order to select a biomass with high storage capacity. The operational parameters applied in both reactors were the same. The systems containing these cultures were stable over time, with a similar storage yield and HA content in both ( $\mathrm{Y}_{\text {STO }}$ of 0.35 and $0.40 \mathrm{Cmmol} / \mathrm{Cmmol}$ and $\mathrm{HA}$ content of $28 \%$ and $36 \%$ in culture 1 and culture 2, respectively) (Figure 2a and b). However, it is worth remarking that the sludge fed with brewery wastewater presented lower substrate uptake rate, giving a longer feast period (Figure 3). Despite of the different acclimation times, both reactors had achieved the stationary state which was characterized by a constant biomass concentration, similar feast times and similar variation in $\mathrm{pH}$ and $\mathrm{DO}$ (dissolved oxygen) values.
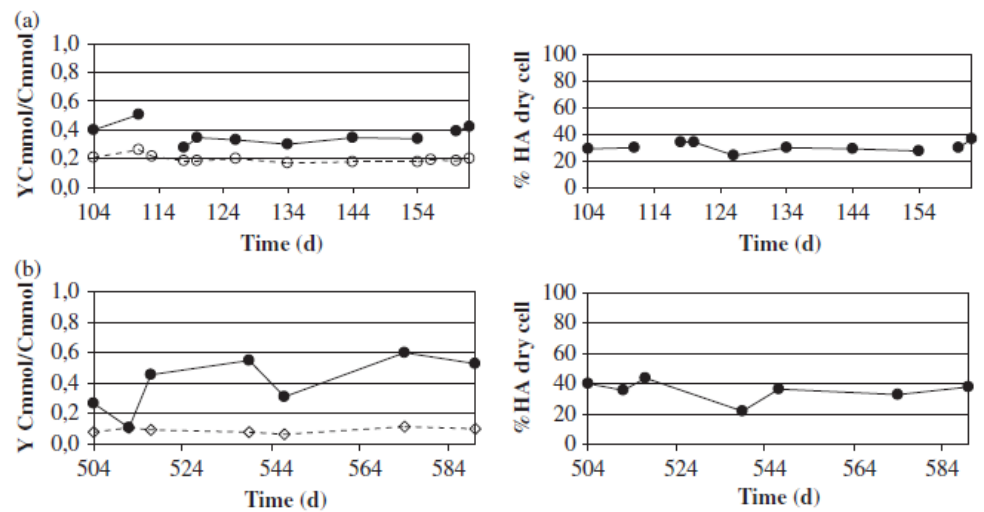

Figure 2: YGROTWH $(\boldsymbol{J})$, YSTO $(\mathbf{K})$ and \%HA $(\mathbf{K})$ obtained during de period of time where the cultures were used to do the assays. Figure (a) is related to culture 1 and figure (b) is associated to culture 2.

In order to determine the viability of using wood mill effluents as substrate in a PHA production process several batch assays were developed. Two assays (assays I and II) were performed with the acidogenic effluents obtained at HRT of 1 and $1.5 \mathrm{~d}$, respectively and sludge acclimated to brewery wastewater (culture 1) obtaining similar storage yields (YSTO) and polymer composition (Table 4 and Figure 4). The slightly higher $\mathrm{Y}_{\text {STO }}$ obtained in assay II could be explained by the lower nitrogen concentration in acidogenic effluent. As known, low nitrogen concentrations limit growth capacity resulting in more carbon directed to the storage process. Several authors (Serafim et al. (2004), Albuquerque et al. (2007), Kumar et al. (2004), Punrattanasin et al. (2006) and Bengtsson et al. (2008b)) observed an increase in HA accumulation when nutrients are limited in the media.

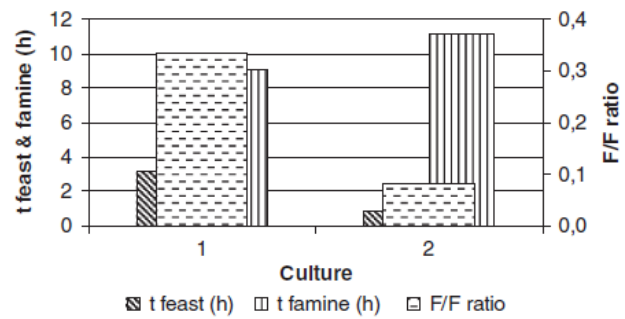

Figure 3: Feast and famine time and feast/famine ratio observed in the operation of the SBR containing the cultures used in this study.

Though VFA composition from the acidogenic effluents attained at different HRTs (Table 1) was different, the polymer composition derived from the batch assays was quite similar, with a high HB monomer content (HB:HV 80:20). In both cases acetic acid was the main acid and the 
valeric and butyric acid contribution was insignificant. Furthermore, other non-VFA contributors for PHA storage could enhance the HB monomer production.

A third assay (assay III) using the same sludge but feeding synthetic media with the same VFA concentration than acidogenic effluent was carried out to study the possible effect of the fermented wood mill effluent on the PHA formation. The results derived from this assay were quite similar to those obtained with real wastewater (Table 4 and Figure 4), therefore it was concluded that substrate inhibition did not take place. Previous works with real wastewater reported in literature mention the possibility of inhibition when a real substrate is used, resulting in lower HA contents than those with a synthetic substrate (Albuquerque et al. 2007). However, in this case the lower HA content achieved are not consequence of a substrate inhibition. As shown Table 4, the specific substrate uptake was higher in the assay developed with real wastewater than that attained in the assay made with synthetic media.

Table 4 : Results derived from the batch assays

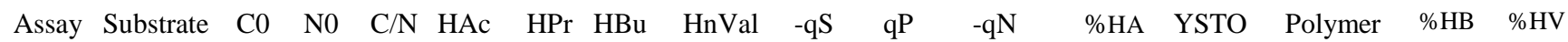

\begin{tabular}{|c|c|c|c|c|c|c|c|c|c|c|c|c|c|c|c|c|}
\hline I & Wood ww & 44.2 & 2.71 & 16 & 68 & 32 & 0 & 0 & 0.063 & 0.012 & 0.010 & 22 & 0.23 & $\mathrm{P}(\mathrm{HB}: \mathrm{HV})$ & 83 & 17 \\
\hline II & Wood ww & 48.3 & 0.46 & 105 & 47 & 38 & 7 & 8 & 0.151 & 0.040 & 0.009 & 27 & 0.35 & $\mathrm{P}(\mathrm{HB}: \mathrm{HV})$ & 81 & 19 \\
\hline III & Synthetic & 46.8 & 0.54 & 87 & 45 & 37 & 8 & 10 & 0.070 & 0.011 & 0.004 & 31 & 0.27 & $\mathrm{P}(\mathrm{HB}: \mathrm{HV})$ & 71 & 29 \\
\hline IV & Wood ww & 44.7 & 0.45 & 99 & 50 & 39 & 6 & 5 & 0.199 & 0.034 & 0.009 & 29 & 0.57 & $\mathrm{P}(\mathrm{HB}: \mathrm{HV})$ & 46 & 54 \\
\hline
\end{tabular}

( $\mathrm{C}_{0}$ : initial substrate concentration as $\mathrm{Cmmol} / \mathrm{L} ; \mathrm{N}_{0}$ : initial nitrogen concentration as $\mathrm{Nmmol} / \mathrm{L} ; \mathrm{Y}_{\mathrm{Sto}}$ : storage yield (Cmmol/Cmmol); - $\mathrm{q}_{\mathrm{s}}$ : specific substrate uptake rate (Cmmol/Cmmol?h); qp: specific polymer production rate $\left(\mathrm{Cmmol} / \mathrm{Cmmol}\right.$ ?h; - $\mathrm{q}_{\mathrm{N}}$ : specific nitrogen uptake rate $(\mathrm{Nmmol} / \mathrm{Cmmol}$ ?h)).

The higher $\mathrm{Y}_{\mathrm{STO}}$ attained in the assay developed with real substrate (assay II) with regard to the assay made with synthetic media (assay III) (Table 4, Figure 4) could be explained by the presence of compounds different from VFA, like alcohols or other simple molecules present in acidogenic effluent, which are contributing to PHA accumulation. This hypothesis is supported by the polymer composition obtained in the assays carried out with real wastewater and the assay with synthetic medium. As shown Table 4, the HB content is higher in the polymer attained with real wastewater (close to 80\%) than in that attained with synthetic media (70\%). Carucci et al. (2010) also observed an increase on the ratio between the PHB formed and the VFA consumed ( 0.74 vs $0.55 \mathrm{COD} / \mathrm{COD})$ when they used real wastewater as substrate instead of acetate. They explained this fact assuming that PHB was also stored from other substrates present in the wastewater.

Finally, in order to determine the effect of the biomass enrichment step on PHA accumulation, other assay (assay IV) was performed using a different inoculum; biomass from a SBR reactor fed with synthetic media (culture 2). As shown in Table 4 and Figure 4 a higher $\mathrm{Y}_{\text {STO }}$ was obtained $(0.57 \mathrm{Cmmol} / \mathrm{Cmmol})$ which indicates that the biomass from the reactor fed with brewery wastewater had lower capacity to accumulate PHA. As mentioned before, although both cultures were enriched under the same operational parameters, the feast time observed in SBR fed with brewery wastewater was longer than that observed in the SBR fed with synthetic media (Figure 2). The longer feast time in the enrichment step using brewery wastewater can influence the storage capacity of the sludge. A relative short feast phase and long famine period is more selective for PHA accumulating bacteria (Johnson et al. 2009). The feast/famine ratio (F/F ratio) is known to affect the sludge storage capacity. If famine stage is not long enough to ensure an internal limitation the culture will adapted to grow instead of storage internal reserves when an 
external substrate is added. Dionisi et al. (2006) observed a loss of the PHA accumulation capacity of the sludge when OLR higher than $25 \mathrm{~g} \mathrm{COD/} \mathrm{L}^{*} \mathrm{~d}$ were fed to the aerobic reactor. They concluded that at the highest OLR tested (25 and $31.25 \mathrm{~g} \mathrm{COD} / \mathrm{L} * \mathrm{~d}$ ) the extent of feast and famine conditions was not enough to select for microorganism with high storage rates and, on the contrary, microorganisms showed a growth response. Albuquerque et al. (2010) also attained higher PHA storage when the F/F imposed in the reactor was low, 0.22 instead of 0.53 . They remark the importance of controlling this parameter as higher feast phases could cause the selective pressure for PHA storage decreasing. Villano et al. (2010) also observed a decreasing storage ability of the biomass at increasing OLR indicating that biomass performance in batch was dependent on its previous cultivation conditions in the SBR.
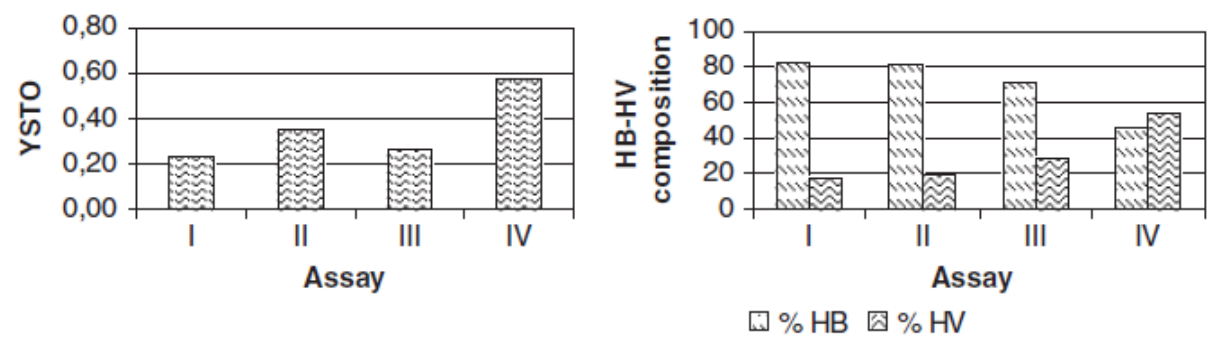

Figure 4: Storage yield (YSTO) and polymer composition obtained during the different batch assays.

\section{Conclusions}

The main conclusions from this work are listed hereafter.

Acidogenic fermentation of a wood mill effluent was carried out at pH 5.5 and 301C and at HRT of 1.0 and $1.5 \mathrm{~d}$ resulting in two different OLR (5.6 and $2.9 \mathrm{~g} \mathrm{COD/L*d).} \mathrm{Reactor} \mathrm{performance}$ was stable during the operation time, obtained similar acidification percentage (37 and 42\%) for the two different HRT applied. However, VFA composition was different, being observed an increase of the long-chain VFA concentration at the higher HRT (1.5 d) tested. Conversion of organic matter into VFA could be improved trying different operational conditions in the acidogenic reactor.

In order to determine the feasibility of using this streamas a substrate for PHA production aerobic batch assays were performed using fermented wood mill effluents obtained at different HRT. The assays were also developed with two different cultures: the first one previously enriched in a SBR fed with fermented brewery wastewater and the second one enriched in a SBR fed with synthetic substrate containing acetate, propionate, butyrate and n-valerate as substrate. Low $\mathrm{Y}_{\text {STO }}$ were attained when the culture enriched in brewery wastewater was used $(0.27$ and $0.35 \mathrm{Cmmol} / \mathrm{Cmmol}$ ), being observed the lowest value when nitrogen was present in the media at high concentration $(0.22 \mathrm{Cmmol} / \mathrm{Cmmol})$.

However, a $\mathrm{Y}_{\mathrm{STO}}$ of 0.57 was achieved when the culture enriched in synthetic media was used. The longer feast time in the enrichment step observed in the SBR fed with brewery wastewater could influence the storage capacity of the sludge, being more competitive those cultures enriched in long SBRcycles where the feast time is shorter like the sludge obtained in the SBR fed with synthetic media.

Wood mill effluent is a good carbon source for PHA production. 


\section{References}

Albuquerque, M. G. E., Eiroa,M., Torres, C., Nunes, B. R.\& Reis, M. A.M. 2007. Strategies for the development of a side stream process for polyhydroxyalkanoates (PHA) production from sugar cane molasses. Journal of Biotechnology 130, 411-421.

Albuquerque, M. G. E., Concas, S., Bengtsson, S. \& Reis, M. A. M. 2010. Mixed culture polyhydroxyalkanoate production from sugar molasses: the use of a 2-stage CSTR system for culture selection. Bioresource technology 101, 7112-7122.

APHA-AWWA-WPCF 1998 Standard Methods for the Examination of Water and Wastewater. 20th ed., Washington DC, USA.

Bengtsson, S., Hallquist, J., Werker A \& Welander, T. 2008a Acidogenic fermentation of industrial wastewater: effects of chemostat retention time and $\mathrm{pH}$ on volatile fatty acids production. Biochemical Engineering Journal 40, 492-499.

Bengtsson, S., Werker, A., Christensson, M. \& Welander, T. 2008b Production of polyhydroxyalkanoates by activated sludge treating a paper mill wastewater. Bioresource Technology 99, 509-516.

Braunegg G., Sonnleitner, B. \& Lafferty R. M. 1978. A rapid gas chromatographic method for the determination of poly-bhydroxybutyric acid in microbial biomass. European Journal of Applied Microbiology and Biotechnology 6, 29-37.

Carucci, A., Dionisi, D., Majone, M., Rolle, E. \& Smurra, P. 2010 Aerobic storatge by activated sludge on real wastewater. Water Research 35(16), 3833-3844.

Coats, E. R., Loge, F. J., Wolcott, M. P., Englund, K.\& McDonald, A. G. 2007 Synthesis of polyhydroxyalkanoates in municipal wastewater treatment. Water Environment Research 79(12), 2396-2403.

Comeau, Y., Hall, K. J. \& Oldham,W. K. 1988 Determination of poly-bhydroxybutyrate and poly-b-hydroxyvalerate in activated sludge by gas-liquid chromatography. Applied Enviromental Microbiology 54(9), 2325-2327.

Dionisi, D., Carucci, G., Papini, M. P, Riccardi, C., Majone, M. \& Carrasco, F. 2005. Olive oil mill effluents as a feedstock for production of biodegradable polymers. Water Research 39, 2076-2084.

Dionisi, D.,Majone, M., Vallini, G., Di Gregorio, S. \& Beccari, M. 2006. Effect of the applied organic load rate on biodegradable polymer production by mixed microbial cultures in a sequencing batch reactor. Biotechnology and Bioengineering 93(1), 76-88.

Johnson K., Jiang, Y., Kleerebezem, R., Muyzer, G. \& Van Loosdrecht, M. C. M. 2009 Enrichment of a mixed culture with a high polyhydroxyalkanoate storage capacity. Biomacromolecules 10(4), 670-676. 
Kumar, S. M., Mudliar, S. N., Reddy, K. M. K. \& Chakrabarti, T. 2004. Production of biodegradable plastics from activated sludge generated from a food processing industrial wastewater treatment plant. Bioresource Technology 95, 327-330.

Lee, S. Y. 1996. Bacterial polyhydroxyalkanoates. Biotechnology and Bioengineering 49, 1-14.

Punrattanasin, W., Randall, A. A. \& Randall, C. W. 2006 Aerobic production of activated sludge polyhydroxyalkanoates from nutrient deficient wastewaters. Water Science \& Technology 54(8), $1-8$.

Satoh, H., Mino, T. \& Matsuo, T. 1992 Uptake of organic substrates and accumulation of polyhydroxyalkanoates linked with glycolysis of intracellular carbohydrates under anaerobic conditions in the biological excess phosphate removal processes. Water Science and Technology 29(5-6), 933-942.

Salmiati, Z., Ujang, M. R., Salim, M. F., Din, Md \& Ahmad, M. A. 2007. Intracellular biopolymer productions using mixed microbial cultures from fermented POME. Water Science and Technology 56(8), 179-185.

Serafim, L. S., Lemos, P. C., Oliveira, R. \& Reis, M. A. M. 2004 Optimization of polyhydroxybutyrate production by mixed cultures submitted to aerobic dynamic feeding conditions. Biotechnology and Bioengineering 87(2), 145-160.

Surthridge, T., Grapes, D., McGrouther, K. \& Slade, A. 2009. Novel methods to convert pulp and paper waste streams into added value products. 7th International Conference on Fate and Effects of Pulp \& Paper Mill Effluents and 9th Symposium on Forest Industry Wastewaters, Canada.

Villano, M., Lampis, S., Valentino, F., Vallini, G., Majone, M. \& Beccari, M. 2010. Effect of hydraulic and organic loads in sequencing batch reactor on microbial ecology of activated sludge and storage polyhydroxyalkanoates. Chemical engineering transactions 20, 187-192. 